\title{
Medievalista
}

\section{Diplomacia visual na Baixa Idade Média portuguesa: os oficiais de armas}

The Visual Diplomacy in the Portuguese Late Middle Ages: the Officers of Arms

\section{Duarte Maria Monteiro de Babo Marinho}

\section{(2) OpenEdition}

\section{Journals}

\section{Edição electrónica}

URL: http://journals.openedition.org/medievalista/1702

DOI: 10.4000/medievalista. 1702

ISSN: 1646-740X

\section{Editora}

Instituto de Estudos Medievais - FCSH-UNL

\section{Refêrencia eletrónica}

Duarte Maria Monteiro de Babo Marinho, « Diplomacia visual na Baixa Idade Média portuguesa: os oficiais de armas », Medievalista [Online], 24 | 2018, posto online no dia 16 março 2019, consultado no dia 01 maio 2019. URL : http://journals.openedition.org/medievalista/1702 ; DOI : 10.4000/ medievalista.1702

\section{Este documento foi criado de forma automática no dia 1 Maio 2019}

(c) IEM 


\title{
Diplomacia visual na Baixa Idade Média portuguesa: os oficiais de armas
}

The Visual Diplomacy in the Portuguese Late Middle Ages: the Officers of Arms

\author{
Duarte Maria Monteiro de Babo Marinho
}

\section{NOTA DO EDITOR}

Data recepção do artigo / Received for publication: 03-04-2017

Data aceitação do artigo / Accepted in revised form: 12-05-2018

\section{Introdução}

1 Estudar a heráldica enquanto código emblemático e, ao mesmo tempo, interligá-la com a diplomacia medieval é uma tarefa complexa, mas também aliciante. A análise paralela destas duas áreas permite compreender melhor os contextos e o pensamento subjacentes à política externa portuguesa, que constitui um prolongamento do poder do rei. Contudo, além das iniciativas régias, também se podem detetar outras, com um cariz mais privado, embora sempre associadas às aspirações da Coroa. Esta abordagem resultou do nosso interesse nas relações externas do reino de Portugal no século XV, dada a frequência com que encontramos oficiais de armas ligados às missões diplomáticas, à semelhança do que ocorria nos demais espaços políticos. Decidimos, assim, aprofundar este tema, tendo em conta o atual panorama historiográfico. Com efeito, salvo algumas referências em estudos heráldicos ${ }^{1}$, em Portugal deparámo-nos com uma reduzida produção historiográfica sobre o tópico heráldica-diplomacia².

2 Para compreender a heráldica da dinastia de Avis, nomeadamente a de D. João I, impõe-se recuar ao tempo de D. Afonso Henriques. Por isso, estabeleceu-se uma metodologia 
comparativa que porventura proporcionará bons resultados, de forma a esclarecer qual a raiz do significado heráldico-propagandístico quatrocentista. Tanto D. Afonso Henriques como os monarcas que se seguiram até D. Afonso III, combateram os mouros, dando continuidade ao processo da "Reconquista" portuguesa"; tal como eles, D. João I também teve o seu processo de conquista, mas em África. O norte de África era visto como uma continuidade do espaço ibérico, uma vez que já tinha sido parte da mesma jurisdição administrativa da Hispânia, originando clivagens nas relações bilaterais entre Portugal e Castela ${ }^{4}$. D. João I patenteia, dessa forma, a sua luta contra os infiéis, tendo na conquista de Ceuta, em 1415, a expressão máxima de tal realidade e que se refletiria ao longo do século $\mathrm{XV}$, como se verificou durante o cativeiro do infante D. Fernando, em Marrocos ${ }^{5}$.

3 Como recorda John Cherry, a elevada taxa de analfabetismo durante a Idade Média leva a que a heráldica passe a ter uma grande importância dado que "estas divisas tenían un significado prático"6. Para além de, segundo Miguel Metelo Seixas, desempenharem "uma função primordial como emblemas visuais de identificação e, por conseguinte, funcionam como fenómeno comunicacional"'. Desta forma, a heráldica, além de ser um elemento visual associado a um modelo social, é um veículo privilegiado de autorrepresentação e de comunicação ao serviço da Coroa $^{8}$. Assim, a armaria constituía um meio priveligidado, ainda que não o único, de transmitir determinadas informações. Embora o seu interesse não se esgotasse no seu potencial comunicativo? .

\section{Heráldica: ciência, arte e técnica - uma comunicação diplomático-visual}

4 É o facto de a heráldica conjugar ciência, arte e técnica, ou seja, uma combinatória de cores, figuras e partições dispostas num escudo de armas (de acordo com as respectivas regras) que permite apurar o seu espaço de comunicação visual de um determinado discurso de honra perante a comunidade internacional. Este sistema de articulação de formas, organização do espaço e respectivos significados, irá perdurar para além do Antigo Regime ${ }^{10}$, continuando a incidir sobre aspetos políticos, culturais e sociais identitários ${ }^{11}$. Na senda de Umberto Eco, trata-se de um sistema complexo, e de grande pendor filosófico e semiológico, usado pela Coroa (e por outros agentes) para transmitir mensagens ideológicas (de teor variável) de modo a captar a atenção dos destinatários ${ }^{12}$. Assim, a heráldica corresponde necessariamente a uma criação histórica que deve ser pensada de acordo com os quadros mentais e culturais do período em que foi produzida, pois, como salienta Miguel Metelo de Seixas, reflete uma afirmação social e política ${ }^{13}$, sempre situada historicamente. As empresas ${ }^{14}$ eram uma das componentes mais importantes do sistema heráldico quando associado à diplomacia: transmitiam a personalização e a ligação do mundo moral à imagem dinástica. Tal implicava que a sua mensagem se fosse desenvolvendo de modo mais personalizado, ao mesmo tempo que acolhia ou se inscrevia num universo de profusas correspondências, características da cultura tardo-medieval ${ }^{15}$. Esta articulação representativa e simbólica permitia, portanto, uma expressão mais eficaz de novas ideias, afirmar-se como um veículo propagandístico dos príncipes, bem como um mostruário de erudiçãa ${ }^{16}$.

5 D. Duarte dá seguimento à empresa paterna, mas introduz modificações originando subsequentes ramificações. O monarca português merece destaque na medida em que terá empreendido uma das reformas de maior relevância e notoriedade no domínio em 
apreço. Com efeito, a ação de D. Duarte no campo heráldico e emblemático coincide com manifestações verificadas a nível europeu que, de forma mais ou menos homogénea, acabariam por se tornar parte integrante da cultura europeia ${ }^{17}$. Dada a importância desta área no estudo da cultura visual europeia, não será de estranhar que, quem se dedique ao estudo da heráldica ou a temas em que seja uma preciosa componente, encare as iniciativas de D. Duarte como um testemunho histórico e reflexo da sociedade que lhe deu origem para múltiplas finalidades, tal como a comunicação política e a projeção externa da Coroa no crepúsculo da Idade Média ${ }^{18}$.

6 Nestas circunstâncias, compreendemos a importância das armas régias enquanto veículos difusores da "imagem consentida" ${ }^{19}$ que a Coroa deixava transparecer para o exterior, uma vez que a armaria atuava como um elo de ligação entre a emblemática principesca e um programa de afirmação de identidade dinástica e de propaganda régia ${ }^{20}$ à qual, a título de exemplo, os infantes D. Pedro, D. Fernando e D. Henrique, bem como o $4^{\circ}$ conde de Ourém, não se alheavam, visto que todos eles tinham oficiais de armas nas suas casas ${ }^{21}$. A propaganda por intermédio da imagem não era só um apanágio da monarquia portuguesa, dado muitas outras terem recorrido à heráldica e aos seus oficiais de armas. Tal como observa Panofsky, a imagem, neste caso a representação heráldica, além de condensar a explicação do que pretendemos transmitir, também se destaca como objeto artístico e apontador de significados, tendo uma íntima e direta relação com o facto, ou seja, a propaganda ${ }^{22}$.

7 A dinastia de Avis teve origens bastardas e, como tal, carecia de aceitação junto da comunidade internacional. De modo a contrariar essa situação, a Coroa fez uso de uma intensa propaganda, tendo a conquista de Ceuta funcionado também como um dos seus principais elementos, refletido na iconografia. Neste particular, sublinha-se ainda o papel da escrita, designadamente da Crónica da Tomada de Ceuta, de Gomes Eanes de Zurara, do Livro da Guerra de Ceuta, de Mateus Pisano; em tudo semelhantes ao caso de Filipe IV de França, abordado exemplarmente por Kantorowicz ${ }^{23}$. A propaganda veiculava uma ideologia precisa relativa aos feitos praticados além do reino, como é o caso da praça norte-africana acima referida. Realidade disponível e precisa, que remete para classificações militares, administrativas, judiciais, entre outras que se plasmam na heráldica, enquanto carga simbólica e identitária nas relações de poder entre poderes ${ }^{24}$.

O sistema heráldico tem por base uma iconografia e visa uma transmissão visual de mensagens retóricas que se condensam numa imagem ${ }^{25} \mathrm{e}$ nos valores simbólicos que o indivíduo, como o monarca, pretendia transmitir ${ }^{26}$, segundo Maria Alice Santos, "através de intermediários que a representam, ao ostentar o seu brasão de armas" ${ }^{27}$. Os oficiais de armas atuavam como plenipotenciários 'anónimos' e percursores de uma diplomacia distinta da convencionalmente praticada pela $\mathrm{Coroa}^{28}$, mas também por outros poderes políticos, dada a grande importância que a imagem representava (e representa). Poderá mesmo afirmar-se com Lévi-Strauss que "toda a cultura pode ser considerada como um conjunto de sistemas simbólicos"29, dado que os símbolos são recorrentes em várias culturas e períodos históricos. Ou seja, a projeção heráldica era o reflexo de um facto segundo o qual se detetava um denominador comum: o reflexo de critérios sociais, individuais ou coletivos de uma comunidade que expressava e refletia o seu status com base nessa iconografia ${ }^{30}$.

9 Ao historiador cabe, também, atentar às dimensões simbólicas da ação social que lhe é transmitida, tendo em conta que a capacidade simbólica representa uma acepção de uma realidade inerente à vida cultural do Homem. Assim, resultado de uma análise que 
reverbera essas mesmas dimensões simbólicas, identifica-se a existência de uma políticaação, política-figura e de uma política-doutrina, veiculadas pela ação diplomática dos oficiais de armas, responsáveis por exprimirem a dimensão do poder, da honra e da glória, bem como o próprio reforço da soberania régia ${ }^{31}$.

Os oficiais de armas podiam ser designados por agentes diplomáticos sem 'rosto' e, muito embora o tema tenha sido já abordado por reconhecidos historiadores da heráldica portuguesa $^{32}$, vale a pena reiterar alguns traços da sua função e sua origem. $O$ oficial de armas cumpria um papel só documentável a partir de 1385, ou seja, não se encontra até à Batalha de Aljubarrota qualquer menção à sua existência. É, no entanto, de estranhar que Portugal não possuísse este cargo, uma vez que todas as entidades políticas com as quais o país mantinha relações diplomáticas já o tinham ${ }^{33}$. Embora alguns autores defendam a existência de oficiais de armas antes de 1385, consideramos que o cargo foi criado por D. João I, tendo este monarca batizado o primeiro oficial com a nomenclatura de rei de armas Portugal. Assim, criado o cargo, nasceu uma nova micro-sociedade, hierarquizada e privilegiada, composta por executores técnicos e com poder de decisão. Eram ordenados segundo uma organização piramidal, estando no topo o rei de armas, seguido do arauto e do passavante. Cada uma destas designações tinha uma origem ou toponímica, ou relacionada com as empresas dos senhores. Para as primeiras são exemplos os reis de armas Portugal e Algarve; os arautos Alcácer, Lisboa, Sacavém e Valença; e os passavantes Guiné e Sintra, como já foram apontados por Severim de Faria e Aires Nascimento ${ }^{34}$. Para as segundas, são exemplos o arauto Balança e o passavante Jamais ${ }^{35}$.

11 Todo e qualquer homem que almejasse exercer este ofício - ou que para ele fosse recrutado - deveria cumprir uma série de condições, explicáveis devido à grande importância de que se revestia o cargo e, também, por se tratarem de indivíduos investidos de plenos poderes inerentes à representatividade do monarca no exterior. Adiante-se ainda que, à semelhança dos embaixadores tout court, estes também se faziam munir "d'une lettre de recommandation", além de serem abrangidos pela imunidade diplomática nas suas deslocações, "au moyen d'un passeport et d'un sauf-conduit"

Identificam-se, como pré-requisitos essenciais para o exercício do ofício, o conhecimento e o domínio de outras línguas - em maior número possível -, dos costumes e da topografia dos locais que iam visitar ${ }^{37}$. Embora se exigissem outras qualidades de cariz psicológico, como a fidelidade, a honestidade, a moderação, a contenção e a discrição. Além destas, impunham-se como fundamentais os conhecimentos técnicos e académicos, in lato sensu, nas áreas da cultura, política e sociedade da Europa Quatrocentista ${ }^{38}$. Esses eram pontos fundamentais que capacitavam estes indivíduos para qualquer tipo de situação no decorrer das suas missões. Por outro lado, eram homens em constante aprendizagem e sujeitos a apresentar resultados ${ }^{39}$, transparecendo a grande importância que o ofício tinha para a Coroa.

13 Apesar de não podermos detetar a origem de muitos desses homens por se tratarem de oficiais anónimos, é possível que alguns se recrutassem nos quadros da administração central, como comprovam os trabalhos de João Paulo de Abreu e Lima, de Alice Santos e de Armando de Carvalho Homem referentes a Gonçalo Caldeira, indivíduo que além de ser oficial de armas também desempenhou importantes cargos no desembargo joanino ${ }^{40}$. Contudo, situações como esta são pontuais: regra geral, os oficiais de armas "apresentamse destituídos de personalidade em si e assumem um lugar em função de quem representam" ${ }^{\prime 1}$. Seja como for, a entrada para o cargo, fossem ou não oriundos do Desembargo, estava sujeita a um ritual específico que passava por um juramento de 
fidelidade, em parte por serem declaradores de verdade, em parte por haver neles um paralelismo com o rei ${ }^{42}$.

O juramento de fidelidade devia-se, também, ao facto de os oficiais de armas pertencerem a um corpo organizado e privilegiado, responsável por funções cerimoniais e diplomáticas da Coroa. Entre essas funções representativas encontram-se os seus contributos na contratação da paz, as negociações de rendição de fortalezas, a veiculação da propaganda régia, a apresentação de cartas de desafio e a participação em grandes eventos cerimoniais e religiosos. Normalmente, o oficial de armas também tinha como função " préparer les aspects matériels et diplomatiques" prévios à chegada dos embaixadores, isto é, e segundo Jacques Paviot, tratava-se de um "proto-

-ambassadeur" " ${ }^{43}$. Vemo-los ainda com responsabilidades de natureza áulica, protocolar e representativa, a juntar ao facto de serem uma extensão da potestas regia. Como consequência, não será de estranhar que muitos cronistas os utilizassem como fontes privilegiadas para os seus relatos ${ }^{44}$.

\section{Os oficiais de armas e as missões diplomáticas}

Tendo feito um levantamento do número de embaixadas portuguesas entre 1431-1475, no âmbito do nosso projeto de doutoramento, contabilizámos a presença de trinta e cinco oficiais de armas. Deste total, uns desempenharam funções eminentemente diplomáticas, outros integraram essas missões sem que se mencionassem as suas incumbências, embora possamos determinar, com relativa segurança, que passavam por funções de tradução e exposição das armas régias, naquilo que, segundo Armindo de Sousa, se identifica como a 'imagem consentida' de um rei. As armas eram o reflexo de parâmetros e de valores culturais, sociais e políticos ${ }^{45}$, alimentando e traduzindo plasticamente o prestígio da Coroa, revelando-se, assim, uma das pedras basilares da política externa do reino.

Estes homens tiveram grande importância no contexto político e diplomático de inícios do século $\mathrm{XV}$, até porque foi com eles que D. João I expressou novas ideias, tendentes à legitimação de uma dinastia bastarda, mediante a presença assídua na Corte da Borgonha dos oficiais de armas portugueses encarregues de diversas missões ${ }^{46}$. Essas medidas, como tem vindo a ser salientado, passaram pela propaganda que, mais tarde, viria a ser enfatizada e usada por D. Duarte, esboçada logo após o falecimento do pai, ajustando a morte deste de treze para catorze, como já salientou Armindo de Sousa ${ }^{47}$. Aliás, em termos de propaganda, o Eloquente foi exímio mestre, pois usou-a subtilmente na sua ação diplomática ${ }^{48}$, tal como o seu pai o fizera, como se pode observar na atuação dos seus diplomatas junto dos concílios de Pisa, Constança e Basileia ${ }^{49}$.

Quanto às missões diplomáticas em que tomaram parte os oficiais de armas, apurámos as seguintes categorias: "correio" (5), "económica" (1), "política" (11), "religiosa" (1), "visita" ${ }^{50}$ (7) e, por fim, num dos campos mais numerosos, "indefinidos" (9), atendendo à falta de informação mais detalhada nos documentos. Identificámos ainda a seguinte distribuição por períodos de governo: D. João I (2), D. Duarte (4), Regência (8) e D. Afonso $\mathrm{V}$ (21); perfazendo o já referido total de trinta e cinco missões.

o desempenho dos oficiais de armas a nível de "correio" diplomático encontra-se medianamente documentado, tendo sido o destino mais comum a Corte do duque de Borgonha. Entre 1432 e 1461, foram enviadas quatro missões: uma no reinado de D. João I (1432-1433), chefiada pelo rei de armas Portugal; no reinado de D. Afonso V verificam-se 
três, em 1454, 1459 e 1461, tendo nelas participado o rei de armas Lisboa, um rei de armas e um passavante “indeterminado". Todas estas missões foram mandatadas com a finalidade de fazer chegar cartas à Borgonha, embora não se saiba qual o seu conteúdo ${ }^{51}$. O mesmo se passou em relação a Aragão quando, em 1416, D. João I enviou o arauto Constantinopla a Alfonso V. Essa missão teve como finalidade pedir cartas de segurança para a embaixada que estava a ser preparada para se dirigir ao concílio de Constança ${ }^{52}$.

No que respeita à "diplomacia económica", o envio de oficiais de armas foi um dos métodos usados pela Coroa para estabelecer este tipo de contactos, de acordo com os dados que foram apurados até ao momento. Seja como for, em 1436, em pleno reinado de D. Duarte, assistimos a uma missão deste género, a incidir no ducado da Bretanha. Todavia, não temos dados que nos possam elucidar sobre o conteúdo, ainda que genérico, desse negócio, preconizado pelo rei de armas Algarve ${ }^{53}$. A questão "política" enquadra-se numa das categorias com maior expressividade ao nível da presença de oficiais de armas. Vemo-los presentes, em primeiro lugar, na Bretanha para onde, em 1436, é enviado o rei de armas Algarve. Porém, a documentação disponível não permite que se aprofunde mais esta questão ${ }^{54}$. Relativamente a Castela, um dos espaços diplomáticos mais importantes no que respeita à política externa de Portugal, detetaram-se três missões do género. Em primeiro lugar, refira-se a de 1463 , que contou com a presença do arauto Alcácer ${ }^{55}$, sem mais se adiantar. Já no ano de 1475, identificámos duas embaixadas, ambas, ao que tudo indica, a cargo do rei de armas Portugal e dirigidas à Coroa castelhana no contexto da Guerra da Sucessão. Na sua primeira missão, foi enviado com a finalidade de transmitir aos reis Católicos os direitos sucessórios de Joana, a Beltraneja ${ }^{56}$; a segunda, empreendida no mesmo ano, teve, além do pendor político, também uma vertente militar ${ }^{57}$. Quanto a França e no contexto das missões políticas, conhecemos duas embaixadas sob responsabilidade de oficiais de armas, ambos arautos. A primeira, de 1463, integra-se na mesma que fôra a Castela, ainda que os assuntos tratados pelo arauto Alcácer não sejam do nosso conhecimento. A segunda, datada de 1475, ocorre nas vésperas do conflito ibérico: o arauto Lisboa leva a notícia ao rei francês da intenção de D. Afonso V entrar militarmente em Castela, para fazer valer os direitos sucessórios da sua sobrinha ${ }^{58}$. A Corte de Inglaterra, em 1462, assistiu à chegada do rei de armas Portugal que aí se tinha deslocado para tratar de questões relacionadas com infrações cometidas aos tratados bilaterais entre os reinos ${ }^{59}$. Por fim, a Cúria Papal assistirá, entre os reinados de D. Duarte e de D. Afonso V, à chegada de quatro oficiais de armas. A primeira missão data de $1437 \mathrm{e}$ foi composta por alguns arautos que acompanharam o $4^{\circ}$ conde de Ourém, tendo um deles exercido a função de intérprete, num diálogo que o conde teve com o duque de Milão ${ }^{60}$. Em pleno reinado do Africano, temos relato de dois intercâmbios diplomáticos: 1458 e 1471. O primeiro, a cargo do rei de armas Portugal ${ }^{61}$, e o segundo sob a responsabilidade do arauto Lisboa ${ }^{62}$. Cada uma delas teve um pendor de obediência, o mesmo será dizer que se trataram de missões políticas ${ }^{63}$.

Também a categoria "diplomacia religiosa" marcou presença, como é disso exemplo uma missão ocorrida em 1450. O arauto Lisboa desloca-se à Coroa de Aragão recebendo, junto de Alfonso $\mathrm{V}$, cartas de recomendação para que vá em segurança às cortes do rei de Chipre e do mestre de Rodes da Ordem do Hospital. Todavia, os dados continuam lacunares, uma vez que não obtivemos informações relativas ao conteúdo da sua presença em Chipre e Rodes, ainda que o mote essencial dessa deslocação se deva a uma peregrinação à Terra Santa ${ }^{64}$. 
21 As missões rotuladas como "visitas" poderiam ter como objetivo, tal como muitas das incógnitas que trataremos de seguida, a visita a uma determinada Corte. Sendo assim, temos notícia de uma a Castela, em 1471, a cargo do arauto Alcácer. Quanto a França, verificaram-se duas, ambas em 1471, sendo uma delas a mesma que se dirigiu a Castela, pelo arauto Alcácer, e a outra foi da responsabilidade do rei de armas Portugal ${ }^{65}$. Inglaterra é o reino para o qual mais missões deste género foram detetadas. Contam-se três presenças: as duas primeiras, datadas de 1445 e 1448, ficaram a cargo de dois reis de armas, o Portugal e o Algarve ${ }^{66}$. A última, de 1452, que teve a finalidade de entregar esmaltes de armoriados ao rei Henrique VI, foi executada pelo arauto Lisboa ${ }^{67}$. Por fim, em relação à Cúria Papal, temos dados sobre uma missão com estas caraterísticas. É datada de 1452, tendo ficado à responsabilidade do arauto Lisboa ${ }^{68}$.

o campo das missões "indefinidas" destaca-se nos dados obtidos sobre a diplomacia praticada por oficiais de armas, com nove missões assinaladas na nossa investigação. 0 ducado da Borgonha, neste contexto, foi o que mais se destacou, com seis missões, tendo quatro ocorrido durante a regência do infante D. Pedro. A primeira data de 1445 e contou com presença do arauto Sacavém e do passavante Guiné, o primeiro da Casa do $4^{\circ}$ conde de Ourém e o segundo da do Infante D. Henrique. Estes oficiais de armas tinham como destino final o Preste João; contudo, o último relato existente é da presença do primeiro arauto Sacavém - em Alexandria ${ }^{69}$ (em 1446 regressou à Borgonha); e, por fim, em 1447, o passavante Valença marcaria presença nessa Corte $^{70}$.

23 Há dois acontecimentos políticos que nos ajudam a explicar o porquê de o território borgonhês ser o destino preferencial das missões diplomáticas confiadas a oficiais de armas. Primeiramente, refira-se o desenvolvimento das relações bilaterais entre Portugal e a Borgonha, devido ao casamento entre a infanta D. Isabel e o duque Filipe o Bom, em 1430. Desta forma, e tendo em conta os fortes laços que uniam os infantes da Ínclita Geração, compreende-se que, a partir desse ano, as missões de cortesia, entre outras, se intensificassem. Contudo, a morte do infante D. Pedro na batalha de Alfarrobeira minou seriamente as relações diplomáticas entre estes dois 'Estados', verificando-se a diminuição das missões de oficiais de armas portugueses ${ }^{71}$. Inglaterra e França são os espaços políticos que restam para concluir esta síntese. Em 1442, o regente mandaria o seu oficial de armas, o arauto Valença, ao primeiro ${ }^{72}$ e, em 1470 , encontramos o rei de armas Portugal, a mando de D. Afonso V, no segundo ${ }^{73}$.

Resta-nos salientar algumas conclusões às quais chegámos após a apresentação e a análise dos dados. Encontramo-nos na presença de agentes diplomáticos 'anónimos', representantes de um corpo de oficiais intimamente relacionado com o mundo cavaleiresco ${ }^{74}$, devotos e fiéis aos senhores leigos que representavam. Partindo das considerações traçadas por Aires Nascimento, com base num manuscrito ao que tudo indica de 1416, e da análise que expusemos ao longo das linhas anteriores, pudemos concluir que os oficiais de armas (reis de armas, arautos e passavantes) se associavam a uma dimensão ideológica, em parte devido à sua indumentária ornamentada com as armas do senhor que serviam ${ }^{75}$. Essa grande proximidade aos seus senhores, bem como ao ambiente cortesão onde estavam inseridos, permitia-lhes obter um profundo conhecimento acerca das estruturas políticas com as quais o reino mantinha algum tipo de relacionamento internacional. De facto, esta interpretação é corroborada tendo em consideração as missões diplomáticas que desempenharam ao longo do período que este estudo engloba. Assim sendo, não estranhamos que eles tenham prestado múltiplos serviços de representação externa da Coroa portuguesa, atuando sob a forma oficial ou 
paralela. No que respeita à primeira, prestavam serviço como mensageiros da paz ou da guerra, efetuavam visitas de cortesia ou anunciavam a chegada de uma embaixada solene, entre outras incumbências. No que diz respeito à diplomacia paralela, v.g., a espionagem, a Coroa aproveitava a inviolabilidade dos oficiais de armas para que estes procedessem à recolha de informações estratégicas ${ }^{76}$.

É neste sentido, finalmente, que se sublinha a sua importância no propagar dos emblemas e, globalmente, da heráldica. A sua circulação e actuação em momentos e espaços decisivos politicamente eram do mesmo modo, uma forma de exibição, exposição e difusão das armas que representavam e apresentavam.

\section{BIBLIOGRAFIA}

Fontes impressas

Monumenta Henricina. Ed. A. J. Dias Dinis. Vol. 2. Coimbra: Comissão Executiva do V Centenário da Morte do Infante D. Henrique, 1960-1974.

NASCIMENTO, Aires - Livro dos Arautos. De Ministerio Armorum. Estudo codicológico, histórico, literário, linguístico. Lisboa: Universidade de Lisboa, 1977. Tese de Doutoramento.

Receitas e Despesas da Fazenda Real de 1384 a 1481. Ed. Jorge Faro. Lisboa: Instituto Nacional de Estatística, 1965.

SANTARÉM, Visconde de - Quadro elementar das relações políticas e diplomáticas de Portugal com as diversas potências do mundo desde o principio da monarchia portugueza até aos nossos dias. Vols. 1 e 3. Paris: J. P. Aillaud, 1842-1860.

SOUSA, D. António Caetano de - Provas da História Genealógica da Casa Real Portuguesa. Vol. 5. Coimbra: Atlântida, 1946-1954.

Estudos

ABRANTES, Marquês de - Introdução ao estudo da Heráldica. Lisboa: Instituto de Cultura e Língua Portuguesa, 1992.

AGUIAR, Miguel - Ideologia Cavaleiresca em Portugal no Século XV. Porto: Faculdade de Letras da Universidade do Porto, 2016. Dissertação de Mestrado.

ALBUQUERQUE, Martim de - "Introdução". in ALBUQUERQUE, Martim de (Org.) - Orações de obediência dos Reis de Portugal aos Sumos Pontífices. Vol. 1. Lisboa: Edições INAPA, 1988.

ARIAS NEVADO, Javier - "El papel de los emblemas heráldicos en las ceremonias funerarias de la Edad Media: siglos XII-XVI”. in LADERO QUESADA, Miguel Ángel (Coord.) - En la España Medieval. Estudios de Genealogía, Heráldica y Nobiliaria. Madrid: Publicaciones de la Universidad Complutense de Madrid, 2006, pp. 49-79.

CAETANO, Marcello - Manual de ciência política e Direito Constitucional. rev. e ampl. por Miguel Galvão-Telles. Coimbra, 1968.

CASTILLO OREJA, Miguel Angel - "Imagen del rey, símbolos de la monarquía y divisas de los reinos: de las series de linajes de la Baja Edad Media a las galerías de retratos del Renacimiento". 
in Galería de Reyes y Damas del Salón de Embajadores, Alcázar de Sevilla. Madrid: Fundación BBVA, 2002, pp. 1-39.

CHERRY, John - Las artes decorativas medievales. Madrid: Ediciones Akal, S. A., 1999.

DUARTE, Luís Miguel - D. Duarte. Mem Martins: Círculo de Leitores, 2005.

ECO, Umberto - Estética. A estrutura do ausente. Introdução à pesquisa semiológica. São Paulo: Editora Perspectiva, 1976.

DUARTE, Luís Miguel - Semiótica e Filosofia da linguagem, Lisboa: Instituto Piaget, 1984.

FARIA, Manuel Severim de - Notícias de Portugal. 2 Edição. Lisboa, 1740.

FARIA, Tiago Viúla de - "Comunicação visual e relações externas: abordagens a partir do caso anglo-português”. in ROSA, Maria de Lurdes; SEIXAS, Miguel Metelo de (Eds.) - Estudos de Heráldica Medieval. Porto: Caminhos Romanos, 2013, pp. 211-224.

FONTES, João Luís Inglês - Percursos e Memória. Do Infante D. Fernando ao "Infante Santo. Cascais: Patrimonia, 2000.

GAMA, José - A Filosofia da cultura portuguesa no "Leal Conselheiro" de D. Duarte. Braga: Fundação Calouste Gulbenkian, 1995.

HILTMANN, Torsten, "[CfP] The History of Heralds in Europe (12th-18th c.). State of the art and new perspectives (Workshop, Münster/Germany, Part 1: March 26-28, 2014)", in Heraldica nova. Medieval Heraldry in social and cultural-historical perspectives (blog on Hypotheses.org). Publicado em: 05/09/2013; Disponível em: http://heraldica.hypotheses.org/528 (consultado em 21/10/2017).

HOMEM, Armando Luís de Carvalho - O Desembargo régio (1320-1433). Porto: Instituto Nacional de Investigação Científica, 1990.

KANTOROWICZ, Ernst H. - Los dos cuerpos del rey. Un estudio de teología política medieval. Madrid: Alianza Universidad, 1985.

LANGHANS, F. P. de Almeida - Heráldica. Ciência de temas vivos. Lisboa: Fundação Nacional para a alegria no Trabalho, 1966.

LIMA, João Paulo de Abreu e - "Oficiais de Armas em Portugal nos Séculos XIV e XV". in Actas do $17^{\circ}$ Congresso Internacional das Ciências Genealógica e Heráldica, vol. 2. Lisboa: Instituto Português de Heráldica, 1986, pp. 309-344.

LIMA, João Paulo de Abreu e - Armas de Portugal. Origem. Evolução. Significado. Lisboa: INAPA, 1998.

LIMA, João Paulo de Abreu e - ; SANTOS, Maria Alice Pereira dos - "Quem foi Gonçalo Caldeira testemunhos para uma análise de funções políticas na corte portuguesa Quatrocentista. De D. João I a D. Afonso V". Revista da Faculdade de Letras. Ciências e Técnicas do Património $1^{\mathrm{a}}$ série, 2 (2003), pp. 335-346.

NOGALES RINCÓN, David - "Las series icnográficas de la realeza castellana-leonesa: siglos XIIXV". in LADERO QUESADA, Miguel Ángel (Coord.) - En la España Medieval. Estudios de Genealogía, Heráldica y Nobiliária. Madrid: Publicaciones de la Universidad Complutense de Madrid, 2006, pp. 81-111.

PANOFSKY, Erwin - Estudos de iconologia. Temas humanísticos na arte da Renascença. Lisboa: Edições Presença, 1986.

PARAVICINI, Werner - “L'Office d'armes: Historiographie, sources, problématique”. Revue du Nord 366-367 (2006), pp. 467-490. 
PARAVICINI, Werner - "Signes et couleurs au Concile de Constance: le témoignage d'un héraut d'armes portugais". in TURRELL, Denise et alii (Eds.) - Signes et couleurs des identités politiques. Du Moyen Age à nos jours. Rennes: Presses Universitaires de Rennes, 2008, pp. 155-188.

PASTOUREAU, Michel - Tratité d'Héraldique. Paris: Picard, 1993.

PAVIOT, Jacques - "Une vie de héraut: Jean de la Chapelle, poursuivant Facuon, héraut Savoie (1421-1444)". Revue du Nord 366-367 (2006), p. 869.

PIDAL DE NAVASCUÉS, Faustino Menéndez - Apuntes de Sigilografía Española. Guadalajara: Aache Ediciones, 1993.

PIDAL DE NAVASCUÉS, Faustino Menéndez - Los emblemas heráldicos. Una interpretación histórica. Madrid: Real Academia de la Historia, 1993.

PIDAL DE NAVASCUÉS, Faustino Menéndez - “Apresentação”. in SEIXAS, Miguel Metelo; ROSA, Maria de Lurdes (Eds.) - Estudos de Herálica Medieval. Porto: Caminhos Romanos, 2013, pp. 15-24.

RAMOS, Manuel - "O impacto de Alfarrobeira nas relações com o ducado de Borgonha”. Revista da Faculdade de Letras. História, 4ª série, 5 (2015), pp. 23-36.

RAMOS, Manuel - "Recent publications - Update May 2017”. in Heraldica nova. Medieval Heraldry in social and cultural-historical perspectives (blog on Hypotheses.org). Publicado em 09/05/2017; Disponível em: http://heraldica.hypotheses.org/5228 (consultado em 21/10/2017).

RIQUER, Martín - Heráldica Castellana em tiempos de los Reys Católicos. Barcelona: Quaderns Crema, 1986.

ROMERO PORTILLA, Paz - Dos monarquías medievales ante la modernidad. Relacionas entre Portugal y Castilla (1431-1479). La Coruña: Universidad da Coruña, 1999.

ROSA, Maria de Lurdes - Longas guerras, longos sonhos africanos. Porto: Fio da Palavra, 2010.

SANTOS, Maria Alice Pereira dos - "A Diplomacia no reinado de D. João I. Breve reflexão sobre os oficiais de armas". in SEIXAS, Miguel Metelo de; ROSA, Maria de Lurdes (Eds.) - Estudos de Heráldica Medieval. Porto: Caminhos Romanos, 2013, pp. 199-207.

SEIXAS, Miguel Metelo de - “As armas e a empresa do rei D. João II. Subsídios metodológicos param o estudo da heráldica e da emblemática nas artes decorativas portuguesas". in MENDONÇA, Isabel Mayer Godinho; CORREIA, Ana Paula (Eds.) - As Artes Decorativas e a Expansão Portuguesa. Imaginário e Viagem. Lisboa: Fundação Ricardo Espirito Santo; Centro Cultura e Científico de Macau; Escola Superior de Artes Decorativas, 2010, pp. 46-82.

SEIXAS, Miguel Metelo de - Heráldica, representação do poder e memória da nação. $O$ armorial autárquico de Inácio de Vilhena Barbosa. Lisboa: Universidade Lusíada, 2011.

SEIXAS, Miguel Metelo de - "Reflexos ultramarinos na heráldica da nobreza de Portugal". in RODRIGUES, Miguel Jasmins (Coord.) - Congresso Internacional Pequena Nobreza nos Impérios Ibéricos de Antigo Regime. Lisboa: Faculdade de Ciências Sociais e Humanas, Universidade Nova de Lisboa, 2012, pp. 1-37.

SEIXAS, Miguel Metelo de - "Bibliografia de heráldica medieval portuguesa". in ROSA, Maria de Lurdes; SEIXAS, Miguel Metelo de (Eds.) - Estudos de Heráldica Medieval. Porto: Caminhos Romanos, 2013, pp. 511-575.

SEIXAS, Miguel Metelo de - ; GALVÃo-TELLES, João Bernardo - "Elementos de uma cultura dinástica e visual: os sinais heráldicos e emblemáticos do rei D. Duarte”. in BARREIRA, Catarina Fernandes; SEIXAS, Miguel Metelo (Eds.) - D. Duarte e a sua época. Arte, cultura, poder e espiritualidade. Lisboa: Instituto de Estudos Medievais, 2014, pp. 257-283. 
SERRÃO, Joaquim Veríssimo - Relações históricas entre Portugal e a França (1430-1481). Paris: Fundação Calouste Gulbenkian; Centro Cultural Português, 1975.

SOUSA, Armindo de - As cortes medievais portuguesas: 1385-1490. Vol. 1. Porto: INIC, 1990.

SOUSA, Armindo de - "Imagens e Utopias em Portugal nos Fins da Idade Média: a imagem consentida do rei”. Revista Portuguesa de História 31-2 (1996), pp. 1-18.

SOUSA, Bernardo Vasconcelos e - D. Afonso IV (1291-1357). Lisboa: Círculo de Leitores, 2005.

STEVENSON, Katie - "The Scottish King of Arms". in HILTMANN, Torsten (Dir.) - Les autres rois. Études sur la royauté comme notion hiérarchique dans la société au bas Moyen Âge et au début de l'époque moderne. München: Oldenbourg Wissenschaftsverlang CmbH, 2010, pp. 64-79.

VILLAROEL GONZÁLEZ, Óscar - "Castilla y el Concilio de Siena: la embajada regia y su actuación". En la España Medieval 30 (2007), pp. 134-135.

\section{NOTAS}

1. Sobre este ponto veja-se SANTOS, Maria Alice Pereira dos - "A Diplomacia no reinado de D. João I. Breve reflexão sobre os oficiais de armas". in SEIXAS, Miguel Metelo de; ROSA, Maria de Lurdes (Eds.) - Estudos de Heráldica Medieval. Porto: Caminhos Romanos, 2013, pp. 199-207. A Autora refere e reflete sobre a presença de oficiais de armas ao serviço de D. João I. Este estudo é um ponto de partida para uma compreensão do que era este tipo de diplomacia.

2. Veja-se "Recent publications - Update May 2017". in Heraldica nova. Medieval Heraldry in social and cultural-historical perspectives (blog on Hypotheses.org). Publicado em 09/05/2017; Disponível em: http://heraldica.hypotheses.org/5228 (consultado em 21/10/2017).

3. Refira-se ainda a participação de D. Afonso IV na batalha do Salado, em auxílio do monarca castelhano. Esta campanha militar teve grande importância para o imaginário português e para a construção da imagem régia (sobre este aspeto veja-se SOUSA, Bernardo Vasconcelos e - D. Afonso IV (1291-1357). Lisboa: Círculo de Leitores, 2005, pp. 214-219).

4. ROMERO PORTILLA, Paz - Dos monarquías medievales ante la modernidad. Relacionas entre Portugal y Castilla (1431-1479). La Coruña: Universidad da Coruña, 1999. Veja-se também ROSA, Maria de Lurdes - Longas guerras, longos sonhos africanos. Porto: Fio da Palavra, 2010. Este trabalho propõe novos olhares acerca da cultura militar e do emprego da força armada ao longo da Idade Média.

5. FONTES, João Luís Inglês - Percursos e Memória. Do Infante D. Fernando ao "Infante Santo. Cascais: Patrimonia, 2000.

6. CHERRY, John - Las artes decorativas medievales. Madrid: Ediciones Akal, S. A., 1999, p. 23.

7. SEIXAS, Miguel Metelo de - "Bibliografia de heráldica medieval portuguesa". in ROSA, Maria de Lurdes; SEIXAS, Miguel Metelo de (Eds.) - Estudos de Heráldica Medieval, p. 514.

8. SEIXAS, Miguel Metelo de; GALVÃo-TELLES, João Bernardo - "Elementos de uma cultura dinástica e visual: os sinais heráldicos e emblemáticos do rei D. Duarte". in BARREIRA, Catarina Fernandes; SEIXAS, Miguel Metelo (Eds.) - D. Duarte e a sua época. Arte, cultura, poder e espiritualidade. Lisboa: Instituto de Estudos Medievais, 2014, p. 279. SEIXAS, Miguel Metelo "Reflexos ultramarinos na heráldica da nobreza de Portugal". in RODRIGUES, Miguel Jasmins (Eds.) - Congresso Internacional Pequena Nobreza nos Impérios Ibéricos de Antigo Regime. Lisboa: Faculdade de Ciências Sociais e Humanas, Universidade Nova de Lisboa, 2012, pp. 1-2.

9. SEIXAS, Miguel Metelo - "Reflexos ultramarinos na heráldica", p. 3.

10. SEIXAS, Miguel Metelo de - Heráldica, representação do poder e memória da nação. 0 armorial autárquico de Inácio de Vilhena Barbosa. Lisboa: Universidade Lusíada, 2011, p. 504 e ss. 
11. LANGHANS, F. P. de Almeida - Heráldica. Ciência de temas vivos. Lisboa: Fundação Nacional para a alegria no Trabalho, 1966, p. 241. SEIXAS, Miguel Metelo de - "Reflexos ultramarinos na heráldica", pp. 2 e 37. FARIA, Tiago Viúla de - "Comunicação visual e relações externas: abordagens a partir do caso anglo-português". in ROSA, Maria de Lurdes; SEIXAS, Miguel Metelo de (Eds.) - Estudos de Heráldica Medieval, p. 212.

12. ECO, Umberto - Estética. A estrutura do ausente. Introdução à pesquisa semiológica. São Paulo: Editora Perspectiva, 1976, pp. 52-85. Do mesmo autor veja-se ainda Semiótica e Filosofia da linguagem, Lisboa: Instituto Piaget, 1984, pp. 35 e 247.

13. Acerca deste assunto veja-se, entre outros, PASTOUREAU, Michel - Tratité d'Héraldique. Paris: Picard, 1993; PIDAL DE NAVASCUÉS, Faustino Ménendez - Los emblemas heráldicos. Una interpretación histórica. Madrid: Real Academia de la Historia, 1993. SEIXAS, Miguel Metelo de "Bibliografia de heráldica medieval portuguesa", p. 514.

14. Trata-se de um emblema pessoal, geralmente escolhido pelo seu titular, podendo transmitir/ representar um ideal de vida, moral ou religioso. Sobre este aspeto veja-se ABRANTES, Marquês de - Introdução ao estudo da Heráldica. Lisboa: Instituto de Cultura e Língua Portuguesa, 1992, pp. 62-70.

15. SEIXAS, Miguel Metelo de; GALVÃO-TELLES, João Bernardo - "Elementos de uma cultura dinástica e visual", p. 268.

16. SEIXAS, Miguel Metelo de; GALVÃO-TELLES, João Bernardo - "Elementos de uma cultura dinástica e visual", p. 274. SEIXAS, Miguel Metelo de - "As armas e a empresa do rei D. João II. Subsídios metodológicos para o estudo da heráldica e da emblemática nas artes decorativas portuguesas". in MENDONÇA, Isabel Mayer Godinho; CORREIA, Ana Paula (Eds.) - As Artes Decorativas e a Expansão Portuguesa. Imaginário e Viagem. Lisboa: Fundação Ricardo Espirito Santo; Centro Cultura e Científico de Macau; Escola Superior de Artes Decorativas, p. 79.

17. PIDAL DE NAVASCUÉS, Faustino Menéndez - "Apresentação". in SEIXAS, Miguel Metelo; ROSA, Maria de Lurdes (Eds.) - Estudos de Herálica Medieval, pp. 15-24.

18. PIDAL DE NAVASCUÉS, Faustino Menéndez - “Apresentação”, pp. 20-24; FARIA, Tiago Viúla de - "Comunicação visual e relações externas", p. 210.

19. A imagem consentida trata-se de uma expressão usada por SOUSA, Armindo de - "Imagens e Utopias em Portugal nos Fins da Idade Média: a imagem consentida do rei". Revista Portuguesa de História 31-2 (1996), pp. 1-18.

20. SEIXAS, Miguel Metelo de; GALVÃO-TELLES, João Bernardo - "Elementos de uma cultura dinástica e visual", p. 268.

21. Receitas e Despesas da Fazenda Real de 1384 a 1481. Ed. Jorge Faro. Lisboa: Instituto Nacional de Estatística, 1965, p. 157; LIMA, João Paulo de Abreu - "Oficiais de Armas em Portugal”, p. 331, n. 101.

22. PANOFSKY, Erwin - Estudos de iconologia. Temas humanísticos na arte da Renascença. Lisboa: Edições Presença, 1986, p 21.

23. KANTOROWICZ, Ernst H. - Los dos cuerpos del rey. Un estudio de teología política medieval. Madrid: Alianza Universidad, 1985, pp. 239-247.

24. SEIXAS, Miguel Metelo de - "Reflexos ultramarinos na heráldica", pp. 4-5, 20; SEIXAS, Miguel Metelo de; GALVÃO-TELLES, João Bernardo - "Elementos de uma cultura dinástica e visual", p. 260; SEIXAS, Miguel Metelo de - “As armas e a empresa do rei D. João II”, p. 54; CASTILLO OREJA, Miguel Angel - "Imagen del rey, símbolos de la monarquía y divisas de los reinos: de las series de linajes de la Baja Edad Media a las galerías de retratos del Renacimiento". in Galería de Reyes y Damas del Salón de Embajadores, Alcázar de Sevilla. Madrid: Fundación BBVA, 2002, p. 94; FARIA, Tiago Viúla de - “Comunicação visual e relações externas", p. 220.

25. PANOFSKY, Erwin - Estudos de iconología, p. 22.

26. CASTILlO OREJA, M. A. - "Imagen del rey", p. 13; SEIXAS, Miguel Metelo de - "Reflexos ultramarinos na heráldica”, p. 20; PANOFSKY, Erwin - Estudos de iconologia, p. 22. 
27. RIQUER, Martín - Heráldica Castellana em tiempos de los Reys Católicos. Barcelona: Quaderns Crema, 1986, p. 41; SANTOS, Maria Alice Pereira dos - “A Diplomacia no reinado de D. João I”, pp. 201-202 (citação). Saliente-se que Torsten Hiltmann sustenta que a história dos oficiais de armas está, em grande parte, subexplorada e que urge a necessidade de reconsiderar o papel destes indivíduos com base em fontes coevas e diversificadas, de forma desmistificar ideias preconcebidas acerca da sua atuação (entre outras publicações deste autor veja-se HILTMANN, Torsten - "[CfP] The History of Heralds in Europe (12th-18th c.). State of the art and new perspectives (Workshop, Münster/Germany, Part 1: March 26-28, 2014)”, Heraldica nova. Medieval Heraldry in social and cultural-historical perspectives (blog on Hypotheses.org). Publicado em: 05/09/2013; Disponível em: http://heraldica.hypotheses.org/528 (consultado em 21/10/2017).

28. FARIA, Tiago Viúla de - "Comunicação visual e relações externas", p. 220.

29. LÉVI-STRAUSS, Claude - Introdución à l'oeuvre de M. Mauss, 1950, Apud GAMA, José - A Filosofia da cultura portuguesa no "Leal Conselheiro" de D. Duarte. Braga: Fundação Calouste Gulbenkian, 1995, p. 24.

30. ECO, Umberto - Semiótica e Filosofia, p. 247; PANOFSKY, Erwin - Estudos de iconología, p. 35; ARIAS NEVADO, Javier - "El papel de los emblemas heráldicos en las ceremonias funerarias de la Edad Media: siglos XII-XVI”. in LADERO QUESADA, Miguel Ángel (Coord.) - En la España Medieval. Estudios de Genealogía, Heráldica y Nobiliaria. Madrid: Publicaciones de la Universidad Complutense de Madrid, 2006, p. 55; CASTILLO OREJA, Miguel Angel - "Imagen del rey", p. 83; SEIXAS, Miguel Metelo de; GALVÃo-TELLES, João Bernardo - "Elementos de uma cultura dinástica e visual", p. 258.

31. SEIXAS, Miguel Metelo de - “As armas e a empresa do rei D. João II", pp. 76-78; FARIA, Tiago Viúla de - "Comunicação visual e relações externas", p. 220; SEIXAS, Miguel Metelo de; GALVÃOTELLES, João Bernardo - "Elementos de uma cultura dinástica e visual”, p. 260; SEIXAS, Miguel Metelo de - "Reflexos ultramarinos na heráldica", pp. 1-37.

32. LIMA, João Paulo Abreu e - Armas de Portugal. Origem. Evolução. Significado. Lisboa: INAPA, 1998, p. 143.

33. LIMA, João Paulo de Abreu - "Oficiais de Armas em Portugal nos Séculos XIV e XV". in Actas do $17^{\circ}$ Congresso Internacional das Ciências Genealógica e Heráldica, vol. 2. Lisboa: Instituto Português de Heráldica, 1986, p. 317.

34. FARIA, Manuel Severim de - Notícias de Portugal. $2^{\mathrm{a}}$ edição. Lisboa, 1740, p. 113; NASCIMENTO, Aires - Livro dos Arautos. De Ministerio Armorum. Estudo codicológico, histórico, literário, linguístico. Lisboa, 1977, p. 36.

35. SEIXAS, Miguel Metelo de - “As armas e a empresa do rei D. João II”, p. 18, nota 60.

36. PAVIOT, Jacques - "Une vie de héraut: Jean de la Chapelle, poursuivant Faucon, héraut Savoie (1421-1444)". Revue du Nord 366-367 (2006), p. 869.

37. STEVENSON, Katie - "The Scottish King of Arms". in HILTMANN, Torsten (Dir.) - Les autres rois. Études sur la royauté comme notion hiérarchique dans la société au bas Moyen Âge et au début de l'époque moderne. München: Oldenbourg Wissenschaftsverlang CmbH, 2010, p. 70.

38. SANTOS, Maria Alice Pereira dos - "A Diplomacia no reinado de D. João I”, p. 200, nota 2.

39. SANTOS, Maria Alice Pereira dos - "A Diplomacia no reinado de D. João I”, p. 199, nota 1.

40. CAETANO, Marcello - Manual de ciência política e Direito Constitucional. rev. e ampl. por Miguel Galvão-Telles. Coimbra, 1968, p. 174; HOMEM, Armando Luís de Carvalho - O desembargo régio (1320-1433). Porto: Instituto Nacional de Investigação Científica, 1990, p. 315; SOUSA, Armindo de As cortes medievais portuguesas: 1385-1490. Vol. 1. Porto: INIC, 1990, pp. 245-246; LIMA, João Paulo de Abreu; SANTOS, Maria Alice Pereira dos - "Quem foi Gonçalo Caldeira - testemunhos para uma análise de funções políticas na corte portuguesa Quatrocentista. De D. João I a D. Afonso V". Revista da Faculdade de Letras. Ciências e Técnicas do Património $1^{\mathrm{a}}$ série, 2 (2003), pp. 335-346.

41. SANTOS, Maria Alice Pereira dos - "A Diplomacia no reinado de D. João I", p. 202. 
42. SANTOS, Maria Alice Pereira dos - "A Diplomacia no reinado de D. João I", p. 200; LIMA, João Paulo de Abreu; SANTOS, Maria Alice Pereira dos - "Quem foi Gonçalo Caldeira", p. 336; SEIXAS, Miguel Metelo de - "Reflexos ultramarinos na heráldica", p. 20.

43. PAVIOT, Jacques - "Une vie de héraut", p. 690.

44. SOUSA, Armindo de - "Imagens e Utopias", pp. 1-18; SEIXAS, Miguel Metelo de - "Reflexos ultramarinos na heráldica", p. 16; PARAVICINI, Werner - "L'Office d'armes: Historiographie, sources, problématique”. Revue du Nord 366-367 (2006), pp. 467-490 ; SANTOS, Maria Alice Pereira dos - "A Diplomacia no reinado de D. João I", pp. 200 e 206. FARIA, Tiago Viúla de - "Comunicação visual e relações externas", p. 217, nota 27.

45. SEIXAS, Miguel Metelo de - "Reflexos ultramarinos na heráldica", pp. 2-3.

46. SANTOS, Maria Alice Pereira dos - "A Diplomacia no reinado de D. João I", pp. 199-207.

47. SOUSA, Armindo de - As Cortes Medievais Portuguesas, Vol. 1, pp. 263-264.

48. SOUSA, Armindo de - As Cortes Medievais Portuguesas, Vol. 1, pp. 263-264; DUARTE, Luís Miguel - D. Duarte. Mem Martins: Círculo de Leitores, 2005, p. 213.

49. Veja-se, entre outros, VILLAROEL GONZÁLEZ, Óscar - "Castilla y el Concilio de Siena: la embajada regia y su actuación”. En la España Medieval 30 (2007), pp. 134-135.

50. O termo "visita" aparece assim referido na fonte publicada em LIMA, João Paulo de Abreu "Oficiais de Armas em Portugal".

51. LANGHANS, F. P. de Almeida - Heráldica. Ciência de temas vivos, p. 241; FARIA, Tiago Viúla de -“Comunicação visual e relações externas”, p. 212; NOGALES RINCÓN, David - "Las series iconográficas de la realeza castellana-leonesa: siglos XII-XV". in LADERO QUESADA, Miguel Ángel (Coord.) - En la España Medieval. Estudios de Genealogía, Heráldica y Nobiliária. Madrid: Publicaciones de la Universidad Complutense de Madrid, 2006, pp. 81-111 (em especial p. 82) \; CASTILLO OREJA, Miguel Angel - "Imagen del rey", pp. 11-39 (em especial p. 13).

52. Monumenta Henricina. Ed. A. J. Dias Dinis. Vol. 2. Coimbra: Comissão Executiva do V Centenário da Morte do Infante D. Henrique, 1960-1974, doc. 114, pp. 237-239.

53. LIMA, João Paulo Abreu e - Armas de Portugal, p. 143.

54. Depreende-se que este Oficial de Armas tenha sido muito fiel à Coroa, nomeadamente ao Regente, Infante D. Pedro - uma proposta que surge à luz das duas doações que foi alvo por parte deste infante. Em 1441-1442 recebe bens que outrora foram da rainha do Leonor; em 1442 recebe mais outro conjunto de bens (LIMA, João Paulo Abreu e - Armas de Portugal, p. 143).

55. SERRÃO, Joaquim Veríssimo - Relações históricas entre Portugal e a França (1430-1481). Paris: Fundação Calouste Gulbenkian; Centro Cultural Português, 1975, p. 88.

56. SANTARÉM, Visconde de - Quadro elementar das relações políticas e diplomáticas de Portugal com as diversas potências do mundo desde o principio da monarchia portugueza até aos nossos dias. Vol. 1. Paris: J. P. Aillaud, 1842-1860, pp. 371-372.

57. SANTARÉM, Visconde de - Quadro elementar, Vol. 1, pp. 375-377.

58. SANTARÉM, Visconde de - Quadro elementar, Vol. 3, pp. 112-113.

59. LIMA, João Paulo de Abreu - "Oficiais de Armas em Portugal”, p. 335.

60. SOUSA, D. António Caetano de - Provas da História Genealógica da Casa Real Portuguesa. Vol. 5. Coimbra: Atlântida, 1946-1954, p. 327; LIMA, João Paulo de Abreu - "Oficiais de Armas em Portugal", p. 329.

61. Monumenta Henricina, Vol. 2, p. 201.

62. FARO, Jorge (Ed.) - Receitas e Despesas da Fazenda Real, p. 79; LIMA, João Paulo de Abreu "Oficiais de Armas em Portugal", p. 336.

63. Sobre este aspeto veja-se (por todos) ALBUQUERQUE, Martim de - "Introdução". in ALBUQUERQUE, Martim de (Org.) - Orações de obediência dos Reis de Portugal aos Sumos Pontífices. Vol. 1. Lisboa: Edições INAPA, 1988.

64. LIMA, João Paulo de Abreu - “Oficiais de Armas em Portugal”, p. 332, ns. 108-109. 
65. HOMEM, Armando Luís de Carvalho - O Desembargo régio, p. 315; LIMA, João Paulo de Abreu; SANTOS, Maria Alice Pereira dos - "Quem foi Gonçalo Caldeira", pp. 335-346.

66. LIMA, João Paulo de Abreu - "Oficiais de Armas em Portugal”, pp. 330 e 332.

67. LIMA, João Paulo de Abreu - "Oficiais de Armas em Portugal”, p. 334.

68. LIMA, João Paulo de Abreu - "Oficiais de Armas em Portugal”, p. 334.

69. LIMA, João Paulo de Abreu - "Oficiais de Armas em Portugal”, p. 331, n. 101.

70. LIMA, João Paulo de Abreu - "Oficiais de Armas em Portugal", p. 331.

71. Veja-se (por todos) RAMOS, Manuel - "O impacto de Alfarrobeira nas relações com o ducado de Borgonha". Revista da Faculdade de Letras. História, 4ª série, 5 (2015), pp. 23-36.

72. LIMA, João Paulo de Abreu - "Oficiais de Armas em Portugal”, p. 330.

73. SERRÃO, Joaquim Veríssimo - Relações históricas, p. 88 e n. 58.

74. Sobre este aspeto, veja-se (por todos) AGUIAR, Miguel - Ideologia Cavaleiresca em Portugal no Século XV. Porto: Faculdade de Letras da Universidade do Porto, 2016. Dissertação de Mestrado.

75. O manuscrito encontra-se na John Rylands Library de Manchester, com a cota arquivística Ms. Lat. 28 (NASCIMENTO, Aires Augusto - Livro de Arautos. De Ministerio Armorum: estudo codicológico, histórico, literário, linguístico. Lisboa, 1977, pp. 30 e ss).

76. NASCIMENTO, Aires Augusto - Livro de Arautos, pp. 36 e 46. Em 2008 foi publicado um trabalho de Werner Paravicini que renovou substancialmente o trabalho de Aires Nascimento (1977). Este autor, apesar de se ter centrado na leitura paleográfica e na tradução do códice, não contemplou no seu estudo a vertente heráldica, como aponta Paravicini (PARAVICINI, Werner - "Signes et couleurs au Concile de Constance: le témoignage d'un héraut d'armes portugais". in TURRELL, Denise et alii (Eds.) - Signes et couleurs des identités politiques. Du Moyen Age à nos jours. Rennes: Presses Universitaires de Rennes, 2008, pp. 155-188).

\section{RESUMOS}

Este estudo aborda os oficiais de armas e a heráldica portuguesa enquanto conjuntos de ciência, arte e técnica, ou seja, possuindo uma carga simbólica reflectida por intermédio de cores, figuras e partições dispostas num escudo de armas, de acordo com as regras heráldicas. Desta forma, aprimorava-se a imagem como marca de comunicação visual de um determinado discurso de honra interligado com a diplomacia medieval. Partindo desta abordagem à heráldica e aos oficiais de armas, vemos que a Coroa transmitia mensagens ideológicas através de veículos privilegiados de autorrepresentação e de comunicação; por outro lado, também se podem compreender melhor os contextos e o pensamento implícitos à política externa portuguesa.

This study aims to discuss the officers of arms and Portuguese heraldry as an aggregate of science, art and technique, that is, possessing symbolic meaning reflected through colours, figures and their organization in a coat of arms - according to heraldic rules. In this way, it would be possible to improve the image and use it as a statement of visual communication of a discourse of honor, deeply connected with medieval diplomacy. From this approach to heraldry and officers of arms, we will, on the one hand, suggest that the Crown conveyed ideological messages trough privileged means of self-representation; and, on the other, that the Portuguese foreign policy context and implicit thought becomes clearer. 
ÍNDICE

Keywords: Visual diplomacy, Medieval diplomacy, Officers of Arms, Propaganda

Palavras-chave: Diplomacia visual, Diplomacia medieval portuguesa, Oficiais de armas, Propaganda

\section{AUTOR}

DUARTE MARIA MONTEIRO DE BABO MARINHO

Universidade do Porto, Faculdade de Letras, Centro de Estudos da População, Economia e Sociedade, 4200, Porto, Portugal

babo.dmmbm@gmail.com 